\title{
PREVENTING JUVENILE DELINQUENCY
}

CEVERAL years ago the United States Children's $S$ Bureau, as part of its programme on juvenile delinquency, published a report about the effectiveness of measures in delinquency prevention. The analysis was based on evaluative studies conducted over the previous twenty-five years or so.

The review led to the conclusion that programmes for the prevention of juvenile delinquency had not been notably effective. This conclusion was tempered by two faets. First, few programmes, relatively speaking, had been evaluated, and most of those not adequately. Secondly, many of the evaluative studies were out of date since they dealt with programmes and methods that to-day might not be considered the best. Moreover, there were hints that good results had been achieved with certain types of delinquent children in certain circumstances. This was notably the case in child guidance work and was perhaps also true of the kind of neighbourhood work associated with the name of Clifford Shaw.

Some of the newer programmes and methods seemed, however, to give promise of more favourable findings. Among those mentioned in the report were various devices for 'reaching out' to youngsters and their parents with services they were unlikely to seek for themselves; for example, group work with delinquent and predelinquent gangs, case work or group work with 'resistant' families. These and other newly devised programmes seemed to be succeeding where older ones had failed and to be benefiting both from the experience of their predecessors and from recent advances in knowledge about human behaviour and motivation.

In an issue of the Annals of the American Academy of Political and Social Science, measures of delinquency prevention and their effectiveness are con- tinued with reports from practitioners and research workers who have been closely associated with these efforts (322, March 1959).

The most striking change, according to Helen $\mathrm{L}$. Wilmer, of the U.S. Department of Health, Education and Welfare, is in the level of sophistication shown in the reports. This is shown in the way the work with delinquent youngsters and their parents is carried on, in the psychological and sociological knowledge underlying the work, and in the methods employed in its evaluation. Much has been learned in all these areas in recent years. These articles show programmes of delinquency prevention both benefiting from that advance and contributing to it.

Perhaps the most important contribution of this series of articles lies in the picture it provides of the kinds of young people who are likely to become chronically delinquent and of the kinds of homes and neighbourhoods they live in. The picture is not a new one but is drawn in a way that reveals, more vividly than usual, the foars, the discouragement and the wish to be like other people that characterize these young people and their parents. The treatment measures described, both those that would improve the environment and those that are directed toward the individuals, take their direction from this knowledge. The knowledge itself is rooted both in the social sciences and in psychology and demonstrates their interrelatedness.

The articles deal with small programmes and, in part, short-lived efforts. Few of them report scientifically established results. Nevertheless, in their conception of what needs to be done and in their suggestions for some ways of doing it, they hold the hope that the problem of delinquency can be reduced if communities are willing to put the effort required into the work.

\section{THE ORIGINS OF LOVE}

$\mathrm{P}$ SYCHOLOGISTS, sociologists and anthropologists commonly hold the view that the infant learns to love through the association of the mother's face, body and other physical characteristics with the alleviation of internal biological tensions, particularly hunger and thirst. Psycho-analysts have tended to emphasize the importance of attaining and sucking at the breast as the basis for affectional development. Recently a number of child psychiatrists have questioned such simple explanations. Some argue that affectionate handling in the act of nursing is a variable of importance, whereas a few workers suggest that the composite activities of nursing, contact, clinging and even seeing and hearing work together to elicit the infant's love for his mother.

It is difficult, if not impossible, to use human infants as subjects for the studies necessary to break through the present speculative impasse. For several years a group at the Primate Laboratory of the University of Wisconsin has been using baby rhesus monkeys in a study that has begun to yield significant insights into the origin of the infant's love for his mother. A report has been prepared by Harry F. Harlow*.

The interest in infant-monkey love grew out of a research programme that involved the separation of monkeys from their mothers a few hours after birth. The investigators were impressed by the deep personal attachments that the monkeys formed for the diaper pads, and by the distress that they exhibited when the pads were removed briefly once a day for the purposes of sanitation. The behaviour of the infant monkeys was reminiscent of the human infant's attachmont to its blankets, pillows or rag dolls. These observations suggested a series of experiments to compare the importance of nursing and all associated activities with that of simple bodily contact in engendering the infant monkey's attachment to its mother. Two surrogate mother monkeys were prepared. One is a bare welded-wire cylindrical form surmounted by a wooden head with a crude face. In the other the welded wire is cushioned by a sheathing of terry-cloth. Eight new-born monkeys

* Scientific American. 200, 6; June 1959. 